\title{
PERSEPSI ORANG TUA TERHADAP LEMBAGA BIMBINGAN BELAJAR DI SAKINAH EDU CENTER LAMONGAN
}

\author{
*(Noer Rafikah Zulyanti \\ Prodi Manajemen, Fakultas Ekonomi, Universitas Islam Lamongan \\ Jl. Veteran No.53A Lamongan \\ Telp. ( 0322 ) 324706, Faks. ( 0322 ) 324706 \\ Email:jpim.unisla@gmail.com
}

\begin{abstract}
ABSTRAK
Perkembangan dunia pendidikan yang pesat sangat mempengaruhi kebiasaan perilaku seseorang untuk meningkatkan kualitas yang lebih baik. Orang tua siswa selaku masyarakat turut memikirkan dan bertanggungjawab atas pendidikan anak mereka (Pongtuluran dan Brahim, 2002. Kekhawatiran orang tua akan pendidikan anak menjadikan mereka untuk berusaha memberikan pendidikan di luar sekolah atau pendidikan nonformal. Pendidikan nonformal diselenggarakan bagi warga masyarakat yang memerlukan layanan pendidikan yang berfungsi sebagai pengganti, penambah, dan/atau pelengkap pendidikan formal dalam rangka mendukung pendidikan sepanjang hayat (Depdiknas, 2009). Salah satu pendidikan nonformal yang meberikan pendidikan belajar kepada anak yaitu lembaga bimbingan belajar (LBB). Penelitian ini dilakukan di lembaga bimbingan belajar Sakinah Edu Center lamongan. Subyek penelitian diambil dari seluruh populasi atau seluruh orang tua dari anak didik lembaga bimbingan sakinah edu center dilamongan yang berjumlah 100 orang tua. Variabel penelitian dalam penelitian ini adalah persepsi orang tua yang mengikutkan anak di lembaga bimbingan belajar di lembaga bimbingan belajar terhadap tenaga pengajar (tentor), fasilitas, dan biaya bimbingan belajar. Hasil dari penelitian ini adalah jika orang tua berpersepsi sangat baik terhadap lembaga bimbingan belajar di sakinah edu center. Skor persepsi siswa terhadap tenaga pengajar (tentor), fasilitas, dan biaya bimbingan belajar adalah 25,25\%-83,80\% pada setiap aspeknya. Sebagian besar orang tua berpersepsi sangat baik terhadap tenaga pengajar (tentor), fasilitas dan biaya pelaksanaan bimbingan belajar. Namun orang tua berpersepsi kurang baik terhadap tingkat biaya kemahalan dalam aspek pelaksanaan bimbingan.
\end{abstract}

Kata Kunci : Persepsi, Lembaga Bimbingan Belajar, Sakinah Edu Center

\section{PENDAHULUAN}

Dengan adanya perkembangan zaman kemajuan disegala bidang yang ada sangat maju pesat termasuk pada bidang pendidikan. Dengan adanya hal ini sangat mempengaruhi kebiasaan perilaku seseorang untuk meningkatkan kualitas yang lebih baik. Dalam menyiapkan generasi yang berkualitas pada bidang pendidikan harus memiliki peran strategis sehingga generasai yang ada di indonesia mampu menciptakan generasi penerus yang berkualitas.

Upaya pemerintah dalam meningkatkat kualitas pendidikan yaitu dengan menyelenggaragakan ujian nasional. Ujian nasional dijadikan tolak ukur untuk mengetahui kualitas pendidikan yang ada di indonesia. Kelulusan ujian nasional ditentukan pemerintah dengan berbagai syarat yang 
telah ditentukan dan setiap tahunnya akan meningkat nilai dari syarat tersebut. Sehingga terbangun motivasi untuk Anak menyiapkan diri dengan ilmu pengetahuan yang dimiliki.

Tuntutan zaman menjadikan Anak harus mempunyai ilmu yang memadai untuk menyiapkan karir di masa depan oleh sebab itu anak harus menempuh pendidikan yang lebih tinggi. Untuk masuk dalam pendidikan yang lebih tinggi anak harus memiliki kemampuan untuk mengikuti ujian masuk sekolah yang persaingannya sangat ketat. Sebagai sekolah formal sudah memberikan bekal ilmu pengetahuan yang sesuai dengan kurikulum yang berlaku kepada anaknya dalam hal ini anak masih kurang percaya diri untuk mengahadapi ujian masuk sekolah.

Orang tua siswa selaku masyarakat turut memikirkan dan bertanggungjawab atas pendidikan anak mereka (Pongtuluran dan Brahim, 2002). Siswa dan orang tua merasa khawatir jika dalam menghadapi perkembangan pendidikan dan persaingan yang begitu ketat untuk masuk sekolah yang diinginkan tidak sesuai yang mereka harapkan oleh karna itu dengan adanya permasalah tersebut pemerintah memberikan solusi yaitu pendidikan non formal dimana pendidikan yang sadar dan teratur tetapi tidak memiliki atauran yang ketat.

Pendidikan nonformal diselenggarakan bagi warga masyarakat yang memerlukan layanan pendidikan yang berfungsi sebagai pengganti, penambah, dan/atau pelengkap pendidikan formal dalam rangka mendukung pendidikan sepanjang hayat (Depdiknas, 2009).
Salah satu pendidikan nonformal yang meberikan pendidikan belajar kepada anak yaitu lembaga bimbingan belajar (LBB).

Bimbingan belajar memberiakan suatu proses bantuan belajar kepada anak untuk mengatasi kesulitan belajar sealin bimbingan belajar yang diberikan sekolah formal bimbingan belajar juga diberikan pada lembaga bimbingan belajar non formal. Hasil penelitianmenunjukkan bahwa bimbingan belajar yang dilakukan di luar pembelajaran memberikan dampak positif terhadap prestasi siswa (Sumarsih, 2010).

Selain itu dampak dari bimbingan belajar anak berpresepsi bahwa bembelajaran tambahan sangat bermanfaat dan efektif diantaranya memberikan penyegaran materi dan mendapat berbagai soal untuk dipecahkan bersama. Biaya bimbingan belajar yang cukup tinggi membuat semua siswa tidak dapat mengikuti kegiatan bimbingan belajar di lembaga bimbingan belajar non formal. Lembaga bimbingan belajar menawarkan tawaran yang menarik berupa program-program atau fasilitas yang memadai. Oleh sebab itu, dilakukan penelitian untuk mengetahui persepsi orang tua terhadap lembaga bimbingan belajar di Sakinah Edu Center .

Berdasarkan latar belakang di atas, permasalahan yang dapat dikemukakan yaitu bagaimanakah persepsi orang tua terhadap lembaga bimbingan belajar di Sakinah Edu Center?

Tujuan dari penilitian ini adalah untuk mendeskripsikan persepsi orang tua terhadap lembaga bimbingan belajar di Sakinah Edu Center. Manfaat dari 
Penelitian ini dapat memberikan pandangan tempat lembaga bimbingan belajar tentang persepsi orang tua terhadap lembaga bimbingan belajar yang memberikan bimbingan belajar di luar lingkungan sekolah sehingga lembaga bimbingan belajar berusaha lebih baik dari sebelumnya. Dengan demikian, kualitas pendidikan anak meningkat.

\section{LANDASAN TEORI}

Persepsi Orang Tua

Persepsi merupakan penilaian seseorang terhadap obyek tertentu. Persepsi adalah aktivitas memanfaatkan indera untuk menanggapi rangsang yang ada di lingkungan sekitar (Syaifudin, 2010). Persepsi sebagai proses bagaimana seseorang menyeleksi, mengatur dan menginterpretasikan masukan-masukan informasi untuk menciptakan gambaran keseluruhan yang berarti (Kotler, 2000). Mangkunegara berpendapat bahwa persepsi adalah suatu proses pemberian arti atau makna terhadap lingkungan.

Persepsi dalam kaitannya dengan lingkungan, yaitu sebagai proses di mana individu-individu mengorganisasikan dan menafsirkan kesan indera mereka agar memberi makna kepada lingkungan mereka (Robbins, 2003). Ada beberapa sifat yang menyertai proses persepsi, yaitu:

1) Konstansi (menetap): Dimana individu mempersepsikan seseorang sebagai orang itu sendiri walaupun perilaku yang ditampilkan berbeda-beda.

2) Selektif: persepsi dipengaruhi oleh keadaan psikologis si perseptor. Dalam arti bahwa banyaknya informasi dalam waktu yang bersamaan dan keterbatasan kemampuan perseptor dalam mengelola dan menyerap informasi tersebut, sehingga hanya informasi tertentu saja yang diterima dan diserap. 3) Proses organisasi yang selektif: beberapa kumpulan informasi yang sama dapat disusun ke dalam pola-pola menurut cara yang berbeda-beda.

Menurut (Azwar, 2010), pengukuran persepsi dapat dilakukan dengan menggunakan Skala Likert, dengan kategori sebagai berikut:

Pernyataan Positif/ Pernyataan Negatif

1. Sangat Setuju: SS

2. Setuju: $\mathrm{S}$

3. Ragu-ragu: R

4. Tidak Setuju:TS

5. Sangat Tidak Setuju:STS

\section{Lembaga Bimbingan Belajar}

Bimbingan merupakan suatu proses pemberian bantuan kepada individu

secara berkelanjutan dan sistematis, dilakukan oleh seseorang ahli yang telah mendapat latihan khusus agar individu dapat memahami diri dan lingkungannya serta dapat mengarahkan dan menyesuaikan diri dengan lingkungan untuk dapat mengembangkan potensi diri secara optimal demi kesejahteraan masyarakat (Eko, 2008). Selaras dengan pendapat tersebut, bimbingan belajar adalah bimbingan yang diarahkan untuk membantu para individu dalam menghadapi dan memecahkan masalahmasalah akademik dilakukan dengan cara mengembangkan suasana belajar mengajar yang kondusif agar terhindar dari kesulitan belajar (Yusu,f 2005).

Bimbingan belajar dapat dilakukan di sekolah maupun diluar lingkungan 
sekolah misalnya di lembaga bimbingan belajar. Lembaga bimbingan belajar

merupakan salah satu wujud partisipasi masyarakat yang turut bertanggungjawab terhadap pendidikan di indonesia (Artati, 2007). Kompetensi profesional tenaga pengajar yang utama adalah menguasai bahan pelajaran dan dapat mengajarkannya dengan jelas dan menarik (Kwartolo, 2005).

Media pembelajaran merupakan segala sesuatu yang dapat digunakan untuk menyalurkan pesan (bahan pembelajaran), sehingga dapat merangsang perhatian, minat, pikiran, dan perasaan siswa dalam kegiatan belajar untuk mencapai tujuan belajar (Santyasa, 2007). Oleh sebab itu, terdapat beberapa hal yang perlu dipertimbangkan untuk menentukan media pembelajaran diantaranya materi yang akan disampaikan, bagaimana memanfaatkan media pembelajaran tersebut dan siapa yang akan menerima materi tersebut (Riandi, 2010).

Berdasarkan uraian diatas dapat disimpulkan bahwa lembaga bimbingan belajar adalah lembaga atau wadah yang memberikan layanan jasa pendidikan berupa bimbingan belajar kepada anak dengan harapan dapat meningkatkan prestasi disekolah sehingga mulculnya keinginan orang tua untuk memberikan bimbingan belajar kepada anak sejak dini.

1. Lembaga Bimbingan Belajar Sakinah Edu Center

Sakinah Edu Center adalah Lembaga Bimbingan Belajar yang telah berdiri kurang lebih sejak 1 tahun yang lalu tepatnya tanggal 22 Nopember 2014 berkedudukan di Jl. Sunan Giri No 4
Lamongan. Sakinah Edu Center sebagai LBB pertama yang mengedepankan perangkat teknologi sebagai media pembelajaran. Sebut saja IT Board, Globe Interactive, Read Book, IT Pen, Ribbo, dan masih banyak lagi perangkat berbasis IT yang digunakan.

Sarana unggulan Sakinah Edu Center lainnya adalah pengajar professional yang bergelar S1 dan S2 sesuai dengan subject menjadikan Sakinah Edu Center menjadi LBB yang pantas dipilih oleh orang tua.

Fasilitas belajar lain yang perlu diperhatikan adalah ruangan belajar yang nyaman dengan nuansa lingkungan yang fun sesuai dengan tag line Sakinah Edu Center Fun Learning Smart Growing bisa terepresentatif di dalamnya.

\section{METODE PENELITIAN}

Penelitian ini dilakukan di lembaga bimbingan belajar Sakinah Edu Center Lamongan. Subyek penelitian diambil dari seluruh populasi atau seluruh orang tua dari anak didik lembaga bimbingan sakinah edu center dilamongan yang berjumlah 100 orang tua. Variabel penelitian dalam penelitian ini adalah persepsi orang tua yang mengikutkan anak di lembaga bimbingan belajar di lembaga bimbingan belajar terhadap tenaga pengajar (tentor), fasilitas, dan biaya bimbingan belajar.

penelitian ini adalah penelitian deskriptif yang termasuk dalam penelitian non experimental. Penelitian ini bertujuan mendeskripsikan atau memberikan gambaran terhadap obyek yang diteliti melalui data sampel atau populasi sebagaimana adanya (Sugiyono, 2005). Pada penelitian ini 
tidak ada perlakuan atau manipulasi dari peneliti.

Penelitian ini dilakukan dengan 2 tahap sebagai berikut:

\section{Tahap persiapan}

Kegiatan yang dilakukan pada tahap persiapan adalah observasi awal untuk mendapatkan dokumen jumlah orang tua yang menitipkan anak pada lembaga bimbingan di sakinah edu center lamongan. Selain itu, pembuatan angket atau kuesioner sebagai instrumen penelitian.

2. Tahap pelaksanaan

Kegiatan yang dilakukan dalam pelaksanaan penelitian yaitu pengambilan data yang ditunjukkan pada Tabel 1 sebagai berikut:

Tabel 1 Tahap pelaksanaan pengambilan data

\begin{tabular}{|l|l|l|}
\hline \multicolumn{1}{|c|}{ Variabel } & \multicolumn{1}{|c|}{ Metode } & \multicolumn{1}{c|}{ Instrumen } \\
\hline Tenaga & Pengisian & Kueisoner \\
Pengajar & Kueisoner & dan lembar \\
Fasilitas & oleh orang tua & observasi \\
Biaya & dan observasi & \\
Bimbingan & oleh observer & \\
Belajar & & \\
\hline
\end{tabular}

Metode yang digunakan untuk mengumpulkan data tentang persepsi orang tua terhadap lembaga bimbingan belajar di LBB Sakinah Edu Center adalah sebagai berikut:

1. Metode angket atau kuesioner.

Penelitian ini menggunakan angket sebagai alat pengumpulan data utama tentang persepsi siswa terhadap lembaga bimbingan belajar yang meliputi tenaga pengajar (tentor), fasilitas, dan biaya pelaksanaan bimbingan. Angket yang digunakan berupa daftar cek lis.

\section{Metode observasi}

Metode observasi dilakukan untuk pengambilan data pendukung tentang orang tua terhadap lembaga bimbingan belajar. Metode ini dilakukan dengan cara melakukan observasi di lembaga bimbingan belajar Sakinah Edu Center dan melakukan tanya jawab terhadap orang tua yang menitipkan anak pada lembaga bimbingan sakinah edu center.

\section{HASIL PENELITIAN DAN PEMBAHASAN}

Hasil dan pembahasan dari penelitian Persepsi orang tua terhadap lembaga bimbingan belajar di sakinah edu center meliputi persepsi siswa terhadap tenaga pengajar (tentor), fasilitas dan biaya bimbingan belajar. Persepsi orang tua tersebut dijabarkan sebagai berikut:

a. Persepsi orang tua terhadap tenaga pengajar (tentor)

Persepsi orang tua terhadap tenaga pengajar di lembaga bimbingan belajar (tentor) dibagi menjadi tiga aspek yaitu aspek kualitas, kedisiplinan dan keramahan. Berdasarkan hasil penelitian diperoleh skor persepsi orang tua terhadap kualitas tentor sebesar $82,45 \%$, persepsi orang tua terhadap kedisiplinan sebesar $85,21 \%$ dan persepsi orang tua terhadap keramahan sebesar $83,80 \%$.

Tenaga pengajar di lembaga bimbingan belajar sakianah edu center dinilai berkualitas oleh Orang tua. Hal ini disebabkan lembaga bimbingan belajar sakinah edu center melakukan seleksi yang cukup ketat terhadap tenaga pengajar dan mengadakan pelatihan pengajaran kepada tenaga pengajar. Selain hal itu tenaga pengajar di lembaga bimbingan belajar 
sakinah edu center sebagian besar guru yang mengajar disekolah tertentu dan lulusan dari universitas yang unggul di daerah lamongan. Tentor di lembaga bimbingan belajar di sakianah edu center tergolong disiplin dan ramah karena dapat memulai dan mengakhiri pembelajaran dengan tepat waktu dan bersikap baik dan tidak galak terhadap anak. Karna Hal ini merupakan peraturan yang ditetapkan oleh lembaga bimbingan belajar sakinah edu center.

b. Persepsi orang tua terhadap fasilitas lembaga bimbingan belajar

Persepsi orang tua terhadap Fasilitas di lembaga bimbingan belajar dibagi menjadi tiga aspek yaitu aspek kenyamanan, kualitas fasilitas dan jumlah fasilitas. Berdasarkan hasil penelitian diperoleh skor persepsi orang tua terhadap kenyamanan sebesar $79,45 \%$, persepsi orang tua terhadap kualitas fasilitas sebesar 82,63\%dan persepsi orang tua terhadap jumlah fasilitas sebesar $79,74 \%$.

Dengan demikian, dapat diketahui bahwa orang tua berpersepsi sangat baik terhadap kenyamanan, kualitas fasilitas dan jumlah fasilitas di lembaga bimbingan belajar sakinah edu center.

c. Persepsi orang tua terhadap biaya bimbingan

Persepsi orang tua terhadap biaya bimbingan di lembaga bimbingan belajar sakinah edu center dibagi menjadi tiga aspek yaitu tingkat mahalnya biaya dan tingkat keringanan biaya. Berdasarkan hasil penelitian diperoleh skor persepsi orang tua terhadap tingkat mahalnya biaya sebesar $25,25 \%$ dan tingkat keringanan biaya sebesar $74,75 \%$.
Dengan demikian dapat diketahui bahwa orang tua berpresepsi sangat setuju terhadap tingkat keringanan biaya yang ada pada lembaga bimbingan belajar di sakinah edu center.

\section{KESIMPULAN DAN SARAN}

Berdasarkan hasil penelitian dan pembahasan dapat diketahui jika orang tua berpersepsi sangat baik terhadap lembaga bimbingan belajar di sakinah edu center. Skor persepsi siswa terhadap tenaga pengajar (tentor), fasilitas, dan biaya bimbingan belajar adalah 25,25\%-83,80\% pada setiap aspeknya. Sebagian besar orang tua berpersepsi sangat baik terhadap tenaga pengajar (tentor), fasilitas dan biaya pelaksanaan bimbingan belajar. Namun orang tua berpersepsi kurang baik terhadap tingkat biaya kemahalan dalam aspek pelaksanaan bimbingan.

\section{DAFTAR PUSTAKA}

Pongtuluran A dan Brahim TK. 2002. Pendidikan berbasiskan masyarakat. Jurnal Pendidikan Penabur 1(1):117-124

Sumarsih A. 2010. Pelaksanaan Program Bimbingan Belajar di Sekolah dalam Menghadapi Ujian Nasional SMA/MA seKabupaten Sragen 2010

(Skripsi). Semarang: Universitas Negeri Semarang

Sugiyono. 2005. Statistika untuk penelitian. Bandung: CV. Alfabeta

Adrian D. 2010. Pengertian Persepsi. Online at http://www.psikomedia.com/artic le/view/PsikologiSosial/2077/PENGERTIAN- 
PERSEPSI/ [diakses 04 Januari 2011]

Eko. 2008. Pengertian Bimbingan.

Online

athttp://eko13.wordpress.com/20 08/03/Pengertian bimbingan.htm [diakses 29 Juli 2010]

Yusuf LNS . 2005. Landasan Bimbingan dan Konseling. Bandung: PT Rosda Karya

Artati RY. 2007. Evaluasi Strategi Pemasaran Pada Lembaga Bimbingan Belajar Primagama Cabang Sutoyo Semarang (Tesis). Semarang: Universitas Diponegoro Semarang

Kwartolo Y. 2005. Menyiapkan Guru yang Berkualitas dengan Pendekatan Micro Teaching. Jurnal Pendidikan Penabur 4(4):98-105

Riandi. 2010. Media Pembelajaran Biologi. Online at http://smamuhammadiyahltasik malayageo.blogspot.com/2010/0 1/penerapan-variasi-metodepembelajaran.html [diakses 3 Mei 2011]

Santyasa IW. 2007. Landasan Konseptual Media Pembelajaran. Makalah disampaikan pada Work Shop Media Pembelajaran bagi Guru-Guru SMAN

Banjarangkan Klungkung. Departemen Pendidikan Nasional. Banjarangkan 10 Januari 2010.

Azwar, Saifudin. 2010. Sikap Manusia Teori dan Pengukurannya. Yogyakarta Pustaka Pelajar

Kotler, Philip. 2000. Marketing Manajemen: Analysis, Planning, Implementation, and Control $9^{\text {th }}$
Edition, Prentice Hall International, Int, New Yersey.

Robbins, S.P. 2003. Perilaku Organisasi. Jilid I. Jakarta: PT INDEKS Kelompok Garmedia. 